\title{
Anti-rabies vaccination induced hepatotoxicity - a case report
}

\author{
Rajashekar Yenneholekoppalu Rajegowda*, Nagashree Belvangla Nanjappa, \\ Narasimhamurthy Kalenahally Muthahanumaiah
}

Department of Pharmacology, Adichunchanagiri Institute of Medical Sciences, B G Nagara, Mandya-571448, Karnataka, India

Received: 11 July 2016

Accepted: 09 August 2016

\section{*Correspondence to:}

Dr. Rajashekar

Yenneholekoppalu Rajegowda, Email: rajashekar.yr@ gmail.com

Copyright: (C) the author(s), publisher and licensee Medip Academy. This is an openaccess article distributed under the terms of the Creative Commons Attribution NonCommercial License, which permits unrestricted noncommercial use, distribution, and reproduction in any medium, provided the original work is properly cited.

\begin{abstract}
Anti-rabies vaccination plays a pivotal role in decreasing the incidence of rabies, a deadly zoonotic viral infection. Adverse effects are significantly reduced and administration became ease on substitution of conventional neuronal vaccination with new non neuronal one. Hepatotoxicity is mainly attributed to many chemicals and drugs, but not so for vaccinations. Here is an isolated case of hepatotoxicity, observed in an old lady, who was administered post exposure anti-rabies prophylaxis treatment .Causal relationship found was probable with widely used standard methods. Her course of the disease was uneventful and her clinical and biochemical status returned back to normal. So anti-rabies vaccination could be hepatotoxic and hence looked for it during its administration.
\end{abstract}

Keywords: Anti-rabies vaccine, Hepatotoxicity

\section{INTRODUCTION}

Rabies is a common zoonotic viral infection of the CNS, caused by lyssavirus type 1 and transmitted to humans by the infected rabid animals. After a prodromal phase, it manifests most often as encephalitis or less frequently as a paralytic form of the disease progressing to coma and death. It causes about 26,000 to 55,000 deaths annually across the globe. ${ }^{1,2}$ To address the magnitude of this problem, various measures were taken and even till today pre and post exposure prophylaxis vaccination remains the mainstay in rabies treatment. It has been found relatively safe and highly efficacious, provided proper vaccination schedule is maintained.

Adverse effect profile of this vaccination appears to be very mild like pain, erythema and induration at the injection site, local lymph node enlargement, fever, headache, abdominal pain, irritability and confusion to severe features like breathlessness, encephalitis and paralysis. Recommended vaccination route, dose and time schedule should be strictly followed especially first 3 doses and to be continued under supervision even in a case of hypersensitivity to it. Hepatotoxicity is a common adverse effect seen with many chemicals and drugs like anti-tubercular drugs (rifampicin, isoniazid and pyrizinamide), acetaminophen, allupurinol, chlorpromazine, anabolic steriods and many more. More than 900 drugs, toxins, and herbs have been reported to cause liver injury, and drugs account for $20-40 \%$ of all instances of fulminant hepatic failure. ${ }^{8}$

It is of two types either type A (pharmacological) - highly predictable, dose dependant and has short latent period or type B (idiosyncratic) - highly non predictable, dose independent and has variable latency period. ${ }^{5}$ Literature 
review showed hardly any documentation of either of these two toxicities with anti-rabies vaccination.

\section{CASE REPORT}

A 70 year old women, a known case of diabetes and hypertension on regular follow up and treatment, was bitten at right little toe, by a stray dog near her house while crossing the road in the early hours of morning. History revealed it was an unprovoked bite of a healthy appearing stray dog. Evening of that day, she reported to nearby hospital where she was given local wound wash, tetanus toxiod IM injection in the gluteal region and the first dose of post exposure prophylaxis of anti-rabies vaccination IM injection in the deltiod region. She was advised to continue her anti- diabetic and antihypertensive medications and to follow vaccination schedule. She was injected IM second and third doses of vaccinations as per schedule in the same hospital. Two days after third dose, she started developing itching all over the body, yellowish discoloration of urine and conjunctiva.

On fourteenth day, she was presented to the same hospital with these new symptoms to get the scheduled forth dose of vaccination, where she was then informed about hepatotoxicity and advised to continue the vaccination.

At this point of time, her visit was paid to our clinic, where a detailed history was elicited and the patient was subjected to clinical and biochemical examinations. No much significant details were obtained except pallor ++ , icterus +++. LFT was abnormal with exceptionally high bilirubin levels and enzyme values are two to three times more higher than the upper limits of the normal.

After this, patient and her attenders were reluctant to continue the scheduled fourth and fifth doses of vaccination despite our assurance and explanation about ill effects of discontinued anti-rabies vaccination. She was treated with medical line of management, advised regular follow up and to report SOS. Her subsequent follow up visits witnessed her signs and symptoms gradually declining, along with liver parameters towards normal. At about four weeks later, she became clinically and biochemically normal with baseline values suggesting an uneventful course of disease with complete recovery.

\section{DISCUSSION}

Conventional anti-rabies vaccination was cumbersome in terms of dose, duration and site of injection and more importantly associated with neurological complications. New generation vaccinations grown either on chick embryo or human diploid cell or vero cell lines are relatively deviod of these neurological adverse effects and convenient to the patients. Hepatotoxicity is a common adverse effect of many drugs, but is rarely found associated with anti-rabies vaccination. More than 900 drugs have been implicated in causing liver injury. ${ }^{3}$ Manifestations of drug induced hepatotoxicity are highly variable, ranging from asymptomatic elevation of liver enzymes to fulminant liver failure. This toxicity is responsible for $5 \%$ of all hospital admissions and $50 \%$ of all acute liver failure requiring liver transplantation. ${ }^{4}$ Drug induced hepatic injury is the most common reason cited for withdrawal of an approved drugs like bromfenac, troglitazone. ${ }^{10,11}$ One of the studies conducted in tertiary care hospital, Rural south India showed Antitubercular drugs as the commonly encountered drugs (44\%) causing hepatotoxicity followed by lipid lowering agents $(41 \%){ }^{9}$

In this case, an old lady, a known case of diabetic and hypertensive on regular oral medications viz, Metformin, low dose Aspirin and Losartan for many months. Scientific reports reveal hardly any association of liver damage with these drugs. History also revealed that she was not following any other medicinal system drugs for her ailments, but she was using tablet ibuprofen for long time on SOS basis for her neck pain.

Using Narango's scale, the relationship between the antirabies vaccination and the hepatotoxicity appears to be probable. ${ }^{6}$ In this case the old lady clinically had the signs and symptoms of hepatotoxicity one week after the administration of first dose of anti-rabies vaccination. CIUMS/RUCOM scale also confirmed probable causality between the cause and the effect. ${ }^{7}$

In this case, the liver enzymes ALT and AST were increased more than four times the upper limit of the normal with a small insignificant rise of ALP, indicating severe hepatocellular damage with minimal affection of biliary system. Total serum protein was almost normal with insignificant altered serum albumin and globulin ratio.

Total serum bilirubin was increased ten times higher than the normal limits with the contribution from both conjugated and unconjugated bilirubin and very high rise in serum suggests severe involvement of hepatic and extra hepatic mechanisms. As serum ALP level was found to be least affected here, a predominant involvement of hepatocytes and RBCs with least involvement of biliary cells could be considered.

\section{CONCLUSION}

Hepatotoxicity more common with drugs and chemicals which may occur even with vaccinations like anti-rabies vaccination. Many such ADR reports may throw more light on causality of this vaccination. However one has to be alert and to exercise caution with all the vaccinations not only for hepatotoxicity, but also for other adverse events.

\section{Funding: No funding sources Conflict of interest: None declared Ethical approval: Not required}




\section{REFERENCES}

1. Rabies Fact Sheet N 99 World Health Organization; 2013. Retrieved 28 February; 2014.

2. Lozano R, Naghavi M, Foreman K, Lim S, Shibuya $\mathrm{K}$, Aboyans V, et al. Global and regional mortality from 235 causes of death for 20 age groups in 1990 and 2010: a systematic analysis for the Global Burden of Disease Study 2010. Lancet 2012;380(9859):2095-128.

3. Friedmann, Grendal SC, James H, McQuaid, Kenneth R. Current diagnosis and tratment in gastroenterology. New York: Lang medival books, McGraw-Hill; 2003:664-679.

4. Pandit A, Sachdeva T, Bafna P. Drug-induced hepatotoxicity: a review. Journal of Applied Pharmaceutical Science. 2012;2(5):233-43.

5. Tripathi KD. Text book of pharmacology. Jaypee Brothers; New Delhi; 2003:78.

6. Narango CA, Busto U, Sellers EM, Sandor P, Ruiz I, Robert EA, et al. A method for estimating the probability of adverse drug reaction. Clin Pharmacol Ther. 1981;30:239-45.

7. Danan G, Benichou C. Causality assessment of adverse reaction to drugs. A novel method based on the conclusion of international consensus meetings: Application to drug-induced liver injuries. J clin Epidemiol. 1993;46:1323-30.

8. Kosanam S, Boyina R. Drug -induced liver injury: a review. International Journal of Pharmacological Research. 2015;5(2):24-30.

9. Jaiprakash H, Narayana S, Jaiprakash M. Druginduced hepatotoxicity in a tertiary care hospital in rural South India. N Am J Med Sci. 2012;4(2):90-3.

10. Hunter EB, Johnston PE, Tanner G, Pinson CW, Awad JA. Bromfenac (Duract)-associated hepatic failure requiring liver transplantation. Am J Gastroenterol. 1999;94:2299-301.

11. Graham DJ, Green L, Senior JR, Nourjah P. Troglitazone-induced liver failure: a case study. Am J Med. 2003;114:299-306.

Cite this article as: Rajegowda YR, Nanjappa NB, Muthahanumaiah NK. Anti-rabies vaccination induced hepatotoxicity - a case report. Int J Basic Clin Pharmacol 2016;5:2280-2. 